Successful Conflict Resolution Between Peacekeepers and NGOs: The Role of Training and Preparation in International Peacekeeping in Bosnia

\author{
Lakshmi Ramarajan \\ The Wharton School \\ University of Pennsylvania \\ Philadelphia, PA 19104-6370
}

E-Mail: Iramarajan@alum.wellesley.edu

Katerina Bezrukova

The Wharton School

University of Pennsylvania

Philadelphia, PA 19104-6370

Tel: (215) 573-5726 Fax: (215) 898-0401

E-Mail: bezrukova@wharton.upenn.edu

\author{
Karen A. Jehn \\ The Wharton School \\ University of Pennsylvania \\ Philadelphia, PA 19104-6370
}

Tel: (215) 898-7722 Fax: (215) 898-0401

E-Mail: jehn@wharton.upenn.edu

Martin Euwema and Nicolien Kop

Utrecht University

Heidelberglaan 1

3584 CS Utrecht

The Netherlands

Tel: 31302534198

Fax: 31302537584

E-Mail: m.euwema@fss.uu.nl

January 2002 


\title{
Successful Conflict Resolution Between Peacekeepers and NGOs: The Role of Training and Preparation in International Peacekeeping in Bosnia
}

\begin{abstract}
We look at the relations between two third-party actors involved in violent conflict situations: international peacekeepers and Non-Governmental Organizations (NGOs) in an ethnopolitical conflict site (i.e. Bosnia). We link the peacekeepers contact with NGOs (frequency and importance) to successful conflict resolution styles. We further link the peacekeepers choice of conflict resolution style to occurrence of problems between NGOs and peacekeepers. We also examine the moderating effects of training and perception of preparedness for the peacekeeping mission on the relationship between frequency of contacts with NGOs (cooperation with NGOs) and conflict resolution with NGOs. We develop hypotheses based on the literature on third party intervention and conflict (Jehn, 1997, Tinsley \& Pillutla, 1998, Zartman, 1995, Rupesinghe, 1995, Herausberger, Calliess \& Merkel 1995), cooperation and competition (Deutsch, 1973), training ( Dupre, 1976, Pruegger \& Rogers, 1994). We test our hypotheses on survey data from a sample of Dutch military peacekeepers on missions between 1995 and 1999 in Bosnia $(\mathrm{N}=907)$. Implications for cooperation and effective intervention on that part of peacekeepers and NGOS in real conflict situations are discussed.
\end{abstract}

Key words: NGO, peacekeeping, conflict resolution, training 


\section{Successful Conflict Resolution Between Peacekeepers and Local NGOs: A Role of Training and Preparation for Peacekeeping Mission in Bosnia}

\section{Introduction}

International intervention in intra-state war has been a feature of the international system over the last decade and still continues. Beginning with Iraq in the 1991 until Sierra Leone in 2001, the United Nations (UN), and other international institutions such as North American Treaty Organization (NATO) and ECOMOG as well as individual states (for example, Britain, South Africa) have sent military peacekeepers into situations of conflict. Belying their name, these peacekeepers have actually been mandated or sometimes forced to create peace, instead of merely inhibit the recurrence of violent conflict between warring parties. It is in such a situation that the subject of our study, the Dutch contingent of NATO Implementation Force (IFOR) and Stabilization Force (SFOR) troops, found themselves in Bosnia in 1995.

Another common feature of international intervention in complex humanitarian emergencies, as events such as Bosnia have come to be known, is the rapid mobilization of non-governmental organizations (NGOs), both international and in some cases, national, at the scene of conflict. These NGOs provide critical resources, material and human, and intervene to prevent even greater civilian casualties and the collapse of social services to those in need. They also work to lay the grounds for future peace and development. Therefore, both NGOs and peacekeepers, co-exist in the same "humanitarian space." As such, the mandates of peacekeepers and NGOs have begun to overlap and can sometimes result in competition over scarce resources. This is one of the first papers that specifically examines this overlap of NGOs and peacekeepers in Bosnia.

Furthermore, for successful intervention in conflict and peacebuilding, it is necessary for the NGOs and peacekeepers to work together. For example, sometimes NGOs need the protection of peacekeepers in order to move personnel and material to needy areas. At 
other times, peacekeepers need the good relations and information of NGOs to provide protection to civilians and encourage resettlement by refugees and the internally displaced. In such a situation, it is critical to examine both the successes and failures of peacekeeper-NGO interactions as it affects their mutual interests and effectiveness. Therefore, our focus is to elucidate the nature of the interaction between these major third party actors. Specifically, we examine the frequency and importance of contacts between NGOs and peacekeepers in Bosnia. We choose these criteria due the increasing numbers and importance of NGOs in conflict zones which leads to inevitable contact between the two third-parties. For example, in Bosnia, during the midst of the crisis in 1993, the number of NGOs doubled from 65 to 126, of which 91 were international and 35 were local (Weiss, 1999).

For NGOs, the fact remains that their ability to gain donations and grants is directly related to their ability to be where there is most need, and that does not always match peacekeeping priorities. For example, when military peacekeeping objectives dictate overt influence and try withhold assistance to persuade local parties to cooperate, NGOs may provide succor and assistance, and restrict the effectiveness of peacekeepers conditionality (Flint, 243). However, in some situations NGOs have been useful to the implementation of peacekeeping operations. For example, in Bosnia, the NATO IFOR and SFOR troops were asked to promote cooperation on the ground by using the leverage of NGOs to create civilian supports to the General Framework Agreements for Peace (Flint, 233). Peacekeepers in almost all situations of conflict, will therefore have to learn to manage relations with NGOs.

Recent literature on peacekeeping operations, however, (ex. the UN's Brahimi Report) has tended to concentrate on the structures, mandates, staffing, etc. of peacekeeping operations. Critique at the level of interaction and implementation in coordination with other international third-party actors in intra-state conflict is still quite limited. Likewise, the literature on NGOs emphasizes coordination and principles, such as "do no harm" (Anderson, 1999) that govern NGO-local party relations in situations of conflict, but rarely examines the competing interests that come into play when dealing with other 
third-party actors, such as peacekeepers. However, we argue that the commonalities and differences in the activities of NGOs and peacekeepers, results in cooperation and competition and it is crucial therefore, to take a closer look at those activities as they can have a detrimental effect on the missions of both.

Another reason for closely examining NGO-Peacekeeping relations and the ability to resolve conflicts among themselves is their common third party status. This is privileged due to common perceptions of impartiality and neutrality. Differences in how NGO workers and peacekeepers present and act upon this shared identity in a conflict situation affects both players. In extreme cases, mishandled conflict can result in putting one or the other party in danger. Impartiality means nothing to local warring parties when a Red Cross Nurse and a UN Commander use the same word to describe a medical program and air strikes, respectively. (Slim, 127).

Civil-military cooperation units (CIMIC units) are specific units within peacekeeping forces that work with NGOs, and international organizations such as the World Bank, UNHCR, etc to resolve such issues. For example, in Iraq, there was one center for coordination between the military operations and the NGOs on the ground. The belief was that information sharing in real time avoids competition between the international intervening parties. However most armies do not have specialized CIMIC units or the resources and time to set up specific cooperation centers. Flint states that in Bosnia, the late arrival by CIMIC troops meant missed opportunities in terms of coordinating policy with NGOs. Thus, training regular troops in cooperation and conflict resolution, management and communication becomes important when the odds and necessity of their being placed in peacekeeping operations has increased considerably in the last decade. Hence, we focus on the examining the specific role of training. Organizational culture differences between the military and civilians, functional relevance and competition, and cross-cultural interactions between peacekeepers and NGO actors can contribute to conflict between the two third-parties, and these can be decreased by various training programs. 
This paper might help to influence the way future peacekeeping missions are designed and how peacekeepers are trained to work with NGOs on the ground, in a successful manner. And though it does not examine the influence of such cooperation on the warring parties, the assumption is that greater cooperation between the two third-party actors will produce greater combined effectiveness, efficiencies in resources and better results in implementing peacekeeping operations in the future.

\section{Research model and definitions}

We look at the relations between two third-party actors involved in violent conflict situations: international peacekeepers and Non-Governmental Organizations (NGOs) in an ethnopolitical conflict site (i.e. Bosnia). The classical conception of peacekeeping envisages a military force intervening between two conflicting parties who have agreed to a cease-fire. Increasingly, peacekeeping missions undertake a variety of tasks, such as civil administration, policing, monitoring and human rights enforcement (Leeds, 2001). Moreover, as in Bosnia, peacekeepers intervene in non-negotiated, non-cease-fire situations. As the Brahimi Report states, " UN operations thus did not deploy into post conflict situations but tried to create them." italics in original (Brahimi Report, UN, 2001). Therefore, we define peacekeeping as a military force intervening in a conflict situation. And we define NGOs as international and/or national non-governmental organizations.

We link the peacekeepers contact with NGOs (frequency and importance) to successful conflict resolution styles. We define conflict resolution style based on five conflict management modes that describe interactant's characteristic types of conflict participation (Blake \& Mouton, 1964). These are forcing, confronting, integrating, avoiding, and compromising (Dallinger \& Hample, 1995). We link the peacekeepers choice of conflict resolution style to occurrence of problems between NGOs and peacekeepers. See Figure 1 for the research model. 
We also examine the moderating effects of training and perception of preparedness for the peacekeeping mission on the relationship between frequency of contacts with NGOs (cooperation with NGOs) and conflict resolution with NGOs. We define training as a set of educational activities offered by an organization to peacekeepers to promote awareness about cross-cultural differences and to improve individuals' skills in communicating with others of diverse backgrounds. Many of the common peacekeeping functions and activities require cultural sensitivity self-awareness, basic communication, negotiation and mediation skills (Leeds 2001).

We develop hypotheses based on the literature on third party intervention and conflict (Jehn, 1997, Tinsley \& Pillutla, 1998, Zartman, 1995, Rupesinghe, 1995, Merkel 1995), cooperation and competition (Deutsch, 1973), training (Dupre, 1976, Pruegger \& Rogers, 1994). We test our hypotheses on survey data from a sample of Dutch military peacekeepers on missions between 1995 and 1999 in Bosnia $(\mathrm{N}=907)$.

The potential contributions of this paper is that it is one of the first studies that investigates the relationship between NGOs and peacekeepers and how coordination between these parties can affect the mission. We have collected a unique data set that provides rich quantitative and qualitative information on this subject to draw valid conclusions and inform future studies. Second, although general accounts of lack of coordination and competition exists, prior empirical evidence is lacking. Therefore, we add to the field by providing an empirical test of the NGOs-peacekeeping contacts. Finally, in this paper we look specifically at the moderating effect of training, which also, to our knowledge, has not been empirically tested in previous research.

\section{Hypotheses:}

Contacts between social units reduces intergroup conflict, and members of different groups start interacting more intensively/frequently, and so develop positive sentiment over time. This increased cohesion leads to cooperation and intensive information exchanges among peacekeepers and NGOs (Deutsch, 1973, Nelson, 1989). We argue that 
this information exchanges will enhance the behaviour repertoire of peacekeepers and provide a positive response in terms of a broader range of conflict management strategies that are successful. For example, literature on information and decision-making provides empirical evidence that greater information exchange leads to the generation of better choices (Ancona \& Caldwell, 1992). Therefore we predict:

\section{Hypothesis1 (H1): The more frequent interaction and the more important the interaction between Peacekeepers and NGOs, the more effective their conflict resolution style.}

Based on the conflict resolution literature and conflict management, effective conflict management style (for example, compromising, integrating) will result in greater trust and confidence and will enhance peacekeeper-NGO cooperation (Lewicki \& Stevenson, 1997; Murnighan, Malhotra \& Weber, 2001). This is likely to lead to less competition, creation of barriers, and less depletion of resources and energy. Finally, less perception of problems between the two parties will result (Deutsch, 1973, 1977).

\section{Hypothesis 2 (H2): The more effective the Peacekeepers conflict resolution style the less problems they will experience in their daily interaction with NGOs.}

We base our rationale for the moderating effect of training on the literature on experiential groups and cross-cultural training. Specifically, research on experiential groups (T-groups) implements the concept of "action research" to solve social problems (Dupre, 1976). Researchers (Campbell, Dunnette, Lawler, \& Weick, 1970) suggest that training similar to $\mathrm{T}$-group training heightens egalitarian attitudes by promoting better understanding of self and others, increasing sensitivity to others, and fostering tolerance to the others' behavior. We argue that this tolerance will lead to better understanding between two parties and will promote cooperation and sensitivity towards the other. Along these lines, research on cross-cultural training (CCT) explains how CCT helps people adjust to a new culture (Pruegger \& Rogers, 1994). Different training models are 
offered to improve trainees' ability to interact effectively with individuals from another culture (Black \& Mendenhall, 1990; Fiedler, Mitchell, \& Triandis, 1971; Harrison, 1992). Evidence for the effectiveness of CCT programs has shown a predominantly positive impact. Therefore, we predict that preparedness \& training will influence the relationship between frequency and importance of contact with NGOs and successful conflict resolution styles.

Hypothesis 3a (H3a): The Peacekeepers perception of their preparation for the mission will moderate the relations between frequency and importance of contact of Peacekeepers with NGOs and conflict resolution styles: That is, when Peacekeepers strongly perceive that they are well prepared, the positive relationship between the frequency and importance of contacts between the two parties and effective conflict resolution will become more positive.

Hypothesis 3b (H3b): The Peacekeepers training for the mission will moderate the relations between frequency and importance of contact of Peacekeepers with NGOs and conflict resolution styles: That is, when Peacekeepers are well trained, the positive relationship between the frequency and importance of contacts between the two parties and effective conflict resolution will become more positive.

Based on the previous discussion we propose the mediating effect of conflict resolution styles on the relationship between frequency and importance of contact and problems faced by peacekeepers in their interaction with NGOs.

Hypothesis 4 (H4): The relationship between frequency and importance of contact of Peacekeepers with NGOs and problems that Peacekeepers faced during their mission will be mediated by their conflict resolution style. 


\section{Method and Measures}

Our data comes from a sample of Dutch military peacekeepers on missions between 1995 and 1999 in Bosnia $(\mathrm{N}=907)$. The survey was sent to all officers who have been on peacekeeping missions between 1995-1999, and low ranked officers of military police as they were trained and have relatively intense contact with parties on the ground. Overall there are 907 military respondents (over 52\% response rate). Additionally, we have 70 non-military expatriates, sent to crisis areas and 50 non-Dutch military from a variety of western countries. The following paragraphs describe our measures.

Frequency of contact between Peacekeepers and NGOs. This was measured by the item Contact with NGO on a Likert scale from 1 (hardly ever) to 5 (daily)

Importance of contact between Peacekeepers and NGOs. This was measured by the item Contact with NGO on a Likert scale from 1(irrelevant) to 5 (very important)

Conflict resolution style. This was measured with the item "how did you in general manage personal frictions and differences of opinion or interest with others during your latest mission" on a Likert scale from 1 (never) to 5 (always). Examples of successful conflict resolution styles included statements such as "I examined issues until I found a solution that really satisfied me and the other party" or "I concurred with the other party." Unsuccessful conflict resolution was indicated by statements such as "I pushed my own point of view" or "I searched for gains"

Problems. This was measured by the item "How frequently did you face problems between your peacekeeping team and NGOs" broken down by frequency (on a scale 1 harldy ever to 5 daily), seriousness (on a scale from 1-not at all serious to 5 -very serious) and personal involvement (one a scale from 1-not at all to 5-heavily involved). 
Perception of preparedness. This was measured by six items. An example of the items used are: "Did you have enough time to prepare yourself for the missions?" measured on a scale of not at all to more that enough and "Were your training and preparation adequate?" measured from not at all to more than enough.

Training. We used two items. First, "looking back at the training for your latest mission, how important to you find knowledge and skills in the following subjects and how do you evaluate the possible training?" on a scale from 1 (not at all) to 10 (absolutely yes). And second, "Are there any other subjects you have missed during preparation for your peacekeeping mission" (no or yes, what subjects?)

\section{Results}

We run t-tests to see whether there is a significant difference between peacekeepers who identified themselves as well-prepared and fully trained versus those who did not. We also run hierarchical regressions to test the moderating effect of training on the relationship between frequency of contact and conflict resolution style. Our results show that there is a significant difference between peacekeepers who identified themselves as well-prepared and fully trained versus those who did not. In particular, peacekeepers who had frequent and important contact with NGOs are likely to find mutually satisfactory solutions or compromise solutions. To be continued!!!

\section{Discussion}

Implications for peacekeeping/NGO relations in future conflict and post-conflict interventions. To be continued!!! 


\section{References}

Ancona, D. \& Caldwell, D. 1992. Bringing the boundary: External activity and performance in organizational teams. Administrative Science Quarterly, 37: 634-665.

Anderson, M.B. 1999. Do no harm : how aid can support peace--or war Boulder, Colo. : Lynne Rienner Publisher.

Black, J. \& Mendenhall, M. 1990. Cross-cultural training effectiveness: A review and a theoretical framework for future research. Academy of Management Review, 15 (1): 113136.

Blake, R. \& Mouton,J. 1964. The Managerial Grid. Houston: Gulf

Campbell, J. Dunnette, M., Lawler, \& Weick, 1970. Managerial behavior, performance, and effectiveness. New York: McGraw-Hill.

Dallinger \& Hample, 1995. Personalizing \& Managing Conflict. The International Journal of Conflict Management, Vol 6 (3) pp 273-289.

Deutsch, M. 1973. The Resolution of Conflict, Yale UP, New Haven.

Dupre, V. 1976. Human relations laboratory training. In Training and Development Handbook, New York: McGraw Hill.

Fiedler, F., Mitchell, T. \& Triandis, H. 1971. The culture assimilator: An approach to cross-cultural training. Journal of Applied Psychology, 55: 95-102.

Harrison, J. 1992. Individual and combined effects of behavior modeling and the culture assimilator in cross-cultural management training. Journal of Applied Psychology, 77 (6): 952-962.

Herausgeber, Calliess, Merkel.(eds). 1995 Peaceful settlement of conflict : a task for civil society : "third party intervention" New York : St. Martin's Press

Flint, E. 2001. Civil Affairs: Soldiers Building Bridges in Aspects of Peacekeeping (Eds. D. S. Gordon \& F. H. Toase). Frank Cass \& Co. Portland, OR. Jehn, K.A. 1997. A qualitative analysis of conflict types and dimensions in organizational groups. Administrative Science Quarterly, 42: 520-557. 
Leeds, C. 2001. Culture, conflict resolution, Peacekeeping training and the D mediator. Paper presented at the IACM Conference, Paris, 24-27 June.

Lewicki, R. \& Stevenson,M. 1997. Trust Development in Negotiation: Proposed Action and the Research Agenda. Paper presented to the conference "Trust and Business: Barriers and Bridges" Depaul University. Murnighan, K. Malhotra, D. \& Weber,M. 2001. Paradoxes of Trust: Empirical and Theoretical Departures from a Traditional Model. Working Paper. Northwestern University.

Pruegger, V. \& Rogers, T. 1994. Cross-cultural sensitivity training: Methods and assessment. International Journal of Intercultural Relations, 18 (3): 369-387.

Rupesinghe. K. (ed.) 1995. Conflict transformation. St. Martin's Press. New York, N.Y. Slim, H. 2001. Positioning Humanitarianism in War: Principles of neutrality, impartiality and solidarity- in Aspects of Peacekeeping (Eds. D. S. Gordon \& F. H. Toase). Frank Cass \& Co. Portland, OR.

Tinsley, C. \& Pillutla, M. 1998. Negotiating in the Unites States and Hong Kong. Journal of International Business Studies, 29 (4): 711-728.

Weiss. 1999 Military Civil interactions: Intervening in Humanitarian crises. Rowman \& Littlefield Publishers, Lanham, MD

Zartman, I.W.(ed.) 1995. Elusive peace : negotiating an end to civil wars. Washington, D.C. : Brookings Institution. 
Figure 1: Research Model

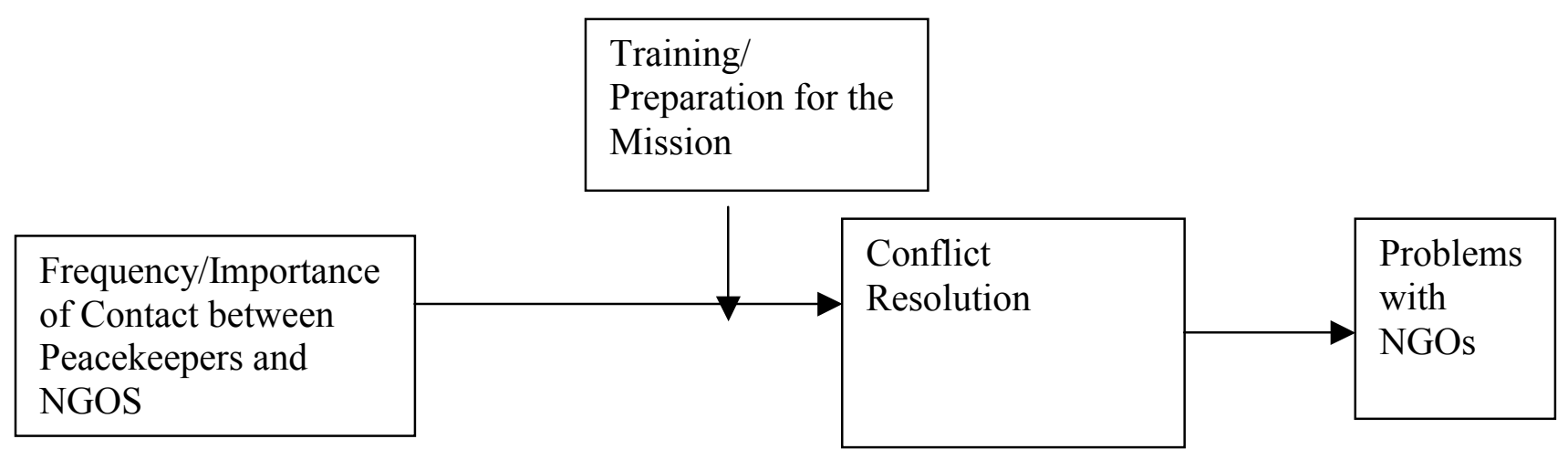

